\title{
Annual Report I
}

\section{Overcoming Barriers to the Remediation of Carbon Tetrachloride through Manipulation of Competing Reaction Mechanisms}

\author{
Principle Investigator: Paul G. Tratnyek, (Oregon Health \& Science University) \\ Co-PIs: James E. Amonette, Eric J. Bylaska, and James E. Szecsody (PNNL).
}

\section{Research Objective}

Most approaches that have been proposed for the remediation of groundwater contaminated with carbon tetrachloride $\left(\mathrm{CCl}_{4}\right)$ produce chloroform $\left(\mathrm{CHCl}_{3}\right)$ as the major product and methylene chloride $\left(\mathrm{CH}_{2} \mathrm{Cl}_{2}\right)$ as a minor product. Both of these products are nearly as persistent and problematic as the parent compound, but competing reaction pathways produce the more desirable products carbon monoxide $(\mathrm{CO})$ and/or formate $\left(\mathrm{HCOO}^{-}\right)$. Results scattered throughout the chemical and environmental engineering literature show that the branching between these reaction pathways is highly variable, but the controlling factors have not been identified. If we understood the fundamental chemistry that controls the branching among these, and related, product-formation pathways, we could improve the applicability of a host of remediation technologies (both chemical and biological) to the large plumes of $\mathrm{CCl}_{4}$ that contaminate DOE sites across the country. This project will provide the first complete characterization of the mechanisms and kinetics of competing degradation reactions of $\mathrm{CCl}_{4}$ through laboratory experiments in simple model systems closely coordinated with theoretical modeling studies. The results provide strategies for maximizing the yield of desirable products from $\mathrm{CCl}_{4}$ degradation, and the most promising of these will be tested in column model systems using real site waters and matrix materials.

\section{Research Progress and Implications}

As of June 2003, work on Tasks 1-3 of this project has been underway for 10 months (since September 2002). These tasks consist of the following:

\section{Objective I. Characterize mechanisms \& kinetics.}

Task 1. Batch Experiments: Quantify the kinetics of all competing product-formation pathways, over a range of conditions relevant to groundwater remediation, using wellmixed batch reactors and analysis primarily by chromatography.

Task 2. Characterization of Reactive Surfaces and Intermediate Species: Determine how the composition and structure of reactive surfaces, and the formation and fate of key reaction intermediates, control the distribution of reaction products formed, using model systems similar to Task 1 but analyzed with complementary spectroscopic and moleculartrapping methods.

Task 3. Theoretical Modeling: Calculate the electronic structure and properties of all relevant contaminant species and intermediates using ab initio quantum mechanical models, and use these results to characterize the controls on branching among reaction products.

Work on Task 1 is occurring mainly at the Oregon Health \& Science University (OSHU), by Dr. Paul Tratnyek and an OHSU Ph.D. student, Vaishnavi Sarathy. Work on Task 2 is 
underway mainly at PNNL by Dr. James Amonette and an EMSL laboratory technician. Work on Task 3 is underway at EMSL by Dr. Eric Bylaska. As scheduled, work on Tasks 4-7 will begin later in year 2 .

So far, work on Tasks 1 and 2 have involved developing and testing the necessary experimental protocols and analytical methods for routinely determining all of the reaction products of carbon tetrachloride reduction over an experimental time course.

This is one aspect of our project that will distinguish it from most previous work done on remediation of carbon tetrachloride, as most previous studies have been based on direct measurement of few species (usually carbon tetrachloride, chloroform, and sometimes methylene chloride or formate) with a significant portion of the product distribution being assigned by difference. We are using several varieties of gas chromatography for carbon tetrachloride, chloroform, and dichloromethane. $\mathrm{CO}$ will be done by packed-column gas chromatography. It appears that we will be able to do formate and chloride in one run using ion chromatography. Batch experiments using these methods are underway using granular iron (at OHSU) and reduced clays (at EMSL).

Progress on Task 3 includes ab initio calculation of the energetic and activation barriers of some of the steps involved in the mechanisms of reduction of carbon tetrachloride and related compounds. Thermo chemical properties that have been calculated include $\square \mathrm{H}^{\mathrm{o}}{ }_{\text {of }}(298.15 \mathrm{~K}), \mathrm{S}^{\mathrm{o}}(298.15 \mathrm{~K}, 1 \mathrm{bar}), \square \mathrm{G}_{\mathrm{S}}(298.15 \mathrm{~K}, 1 \mathrm{bar})$ for the substituted chloromethyl radicals and anions: $\mathrm{CH}_{\mathrm{y}} \mathrm{Cl}_{2-\mathrm{y}} L^{*}$, and $\mathrm{CH}_{\mathrm{y}} \mathrm{Cl}_{2-\mathrm{y}} L^{-}$, for y $=0,1,2$ (with $L^{-}=\mathrm{F}^{-}$, $\mathrm{OH}^{-}, \mathrm{SH}^{-}, \mathrm{NO}_{3}^{-}, \mathrm{HCO}_{3}^{-}$and $\left.\mathrm{x}=0,1,2,3\right)$. A computational method was developed to calculate barriers for an outer-sphere dissociative electron transfer reaction involving carbon tetrachloride. The activation energy at the crossing point is lower in solution phase. These results are consistent with Saveant's mechanistic model of dissociative reduction.

\section{Planned Activities}

For the remainder of Project Year 1, the work on OHSU on Task 1 will focus on batch experiments using $\mathrm{Fe}(0)$ as the reductant and determining branching ratios among products as a function of time and experimental conditions. The PNNL effort on Task 2, during the remainder of Project Year 1, will focus on identifying and quantifying the key intermediate species in the $\mathrm{CCl}_{4}$ degradation reaction by trapping them with agents that can be detected by either UV or EPR spectroscopy. Simple experiments will involve addition of trapping agents at the same time as $\mathrm{CCl}_{4}$ to suspensions containing $\mathrm{Fe}(0)$ or $\mathrm{Fe}(\mathrm{II})$, and then extracting them after various time periods. We will also attempt some stopped-flow kinetic experiments using EPR spectroscopy to monitor the rate of generation of the spin-trapped species in-situ. In Task 3, we will perform a theoretical investigation of the thermodynamic properties of all relevant species and intermediates for the reduction and hydrolysis of $\mathrm{CCl}_{4}$ using ab initio models and energetic data available from experiments. This work will involve the development of strategies for estimating enthalpies of formation based on isodesmic approaches.

In Project Year 2, Task 2 will complete the intermediate-identification studies and focus on completing the characterization of solid surfaces for Fe species. In Task 3, we will conduct a theoretical investigation to determine the barriers for reactions of all relevant reaction pathways for reduction and hydrolysis of $\mathrm{CCl}_{4}$ using ab initio models. This work 
will feed into the development of a theoretical framework for predicting product distributions as a function of key reaction parameters in Task 5, which will start in the latter part of the year. We will also start the column studies for Task 6 in the latter part of Project Year 2.

Table 2. Updated time line for the major objectives and general tasks.

\begin{tabular}{|c|c|c|c|c|c|c|c|c|c|c|c|c|}
\hline \multirow[b]{2}{*}{ Objectives/Tasks } & \multicolumn{4}{|c|}{ Year I } & \multicolumn{4}{|c|}{ Year II } & \multicolumn{4}{|c|}{ Year III } \\
\hline & $1 / 4$ & $2 / 4$ & $3 / 4$ & $4 / 4$ & $1 / 4$ & $2 / 4$ & $3 / 4$ & $4 / 4$ & $1 / 4$ & $2 / 4$ & $3 / 4$ & $4 / 4$ \\
\hline \multicolumn{13}{|l|}{ I. Characterize Mechanism \& Kinetics } \\
\hline 1. Batch experiments & \multicolumn{4}{|c|}{ Student \& Tratnyek } & \multicolumn{4}{|c|}{ Student \& Tratnyek } & & & & \\
\hline 2. Reactive Surfaces \& Intermediates & \multicolumn{8}{|c|}{ Staff \& Amonette } & & & & \\
\hline 3. Theoretical calculations & \multicolumn{4}{|c|}{ Bylaska } & \multicolumn{4}{|c|}{ Bylaska \& Others } & & & & \\
\hline \multicolumn{13}{|l|}{ II. Derive Control Strategies } \\
\hline 4. Batch experiments & & & & & \multicolumn{4}{|c|}{ Student \& Tratnyek } & \multicolumn{4}{|c|}{ Student \& Tratnyek } \\
\hline 5. Mechanistic modeling & & & & & \multicolumn{4}{|c|}{ Bylaska \& Others } & & & & \\
\hline \multicolumn{13}{|l|}{ III. Test Control Strategies } \\
\hline 6. Column experiments & & & & & \multicolumn{4}{|c|}{ Technician \& Szecsody } & \multicolumn{4}{|c|}{ Technician \& Szecsody } \\
\hline 7. Reactive-transport modeling & & & & & & & & & & & ody & \\
\hline
\end{tabular}

\section{Information Access}

This project is a new start. However, some effort on the project has been spent towards completing two publications that are nearly complete in early 2003:

Miehr, R., Tratnyek, P. G., Bandstra, J. Z., Scherer, M. M., Alowitz, M., and Bylaska, E. J. (2003) "The diversity of Contaminant Reduction Reactions by Zero-valent Iron: Role of the Reductate." (Submitted to Environmental Science and Technology, Spring 2003).

Bylaska, E. J., Dixon, D. A., Apra, E., Felmy, A. R., and Tratnyek, P. G. (2003) "The Energetics of the Hydrolysis, Dehydrohalogenation, and Reductive Dehalogenation for 4,4'-DDT and 1,1,1-Trichloroethane." (Submitted to the Journal of Physical Chemistry, A, Spring 2003). 